\title{
Topographic Patterns of Brain Activity in Response to Swim Stress: Assessment by 2-Deoxyglucose Uptake and Expression of Fos-like Immunoreactivity
}

\author{
Gary E. Duncan, Kevin B. Johnson, and George R. Breese
}

Brain and Development Research Center, and Departments of Psychiatry, Pharmacology and Cell Biology and Anatomy, School of Medicine, University of North Carolina at Chapel Hill, Chapel Hill, North Carolina 27599

\begin{abstract}
Alterations in brain activity patterns were assessed in response to swim stress by immunocytochemical detection of Fos-like immunoreactivity (Fos-LI) and high-resolution autoradiographic imaging of ${ }^{14} \mathrm{C}$-2-deoxyglucose (2-DG) uptake. The stress paradigm investigated was a classic behavioral screen for antidepressant drug activity, the forced swim test. One of the most pronounced effects produced by swim stress was an increase in 2-DG uptake and induction of Fos-LI in a restricted region of the lateral septal nucleus. Specific "limbic" cortical regions, including the medial prefrontal, ventrolateral orbital, and cingulate cortices, also exhibited both increased 2-DG uptake and expression of Fos-LI in response to swim stress. In the hypothalamic paraventricular nucleus of swim-stressed rats, Fos-LI was induced but no change in 2-DG uptake was apparent. Since the specific swim stress protocol used is a behavioral screen for antidepressant drugs, the effects of imipramine on stressinduced alterations in 2-DG uptake and induction of Fos-LI were examined. The stress-induced increase in 2-DG uptake in the lateral septum was blocked by treatment with imipramine, but treatment with imipramine had no effect on induction of Fos-LI in the same region. Neither 2-DG uptake nor Fos-LI expression was altered by imipramine treatment in the cortical regions influenced by swim stress. Administration of imipramine alone under basal conditions produced a robust induction of Fos-LI in the central nucleus of the amygdala and in the dorsal lateral subdivision of the bed nucleus of the stria terminalis. No effect of imipramine treatment on 2-DG uptake was apparent in these latter regions. The results provide insights into topographic patterns of brain activity associated with swim stress and neuroanatomically selective actions of imipramine. The different and complementary information obtained by assessment of Fos-LI and 2-DG uptake illustrates the utility of applying both functional mapping approaches to examine neuroanatomical correlates of behavioral states and drug treatment.
\end{abstract}

IKey words: 2-deoxyglucose, c-fos, antidepressants, stress, metabolic activity, imipramine, lateral septum, paraventricular nucleus, amygdala]

\footnotetext{
Received Nov. 18, 1992; revised Mar. 16, 1993; accepted Mar. 23, 1993

This work was supported by MH-39144, MH-33127, AA-08024, and HD03110 .

Correspondence should be addressed to Dr. Gary E. Duncan, University of North Carolina, 224 BDRC, CB \#7250, Chapel Hill, NC 27599.

Copyright (C) 1993 Society for Neuroscience $0270-6474 / 93 / 133932-12 \$ 05.00 / 0$
}

There are a variety of pathological conditions in which stress may be a predisposing factor, including gastric ulcers (Weiss, 1971), cardiovascular disease (Glass, 1977), and affective disorders (Anisman and Zacharko, 1982). A better understanding of functional neuroanatomical responses to stress could facilitate development of therapies for such stress-related conditions. Noninvasive techniques are available to identify brain regions that are components of neural circuits activated in response to stress. One of the most widely used approaches to explore functional neural responses in freely behaving rats is autoradiographic assessment of radiolabeled 2-deoxyglucose (2-DG) uptake. This approach is based on the observations that energy for brain metabolism is derived almost exclusively from glucose and 2-DG is transported into brain tissue in proportion to the rate of glucose utilization (Sokoloff et al., 1977). In addition to 2-DG uptake, immunocytochemical assessment of the induction of Fos protein, the product of the protooncogene c-fos, has proven useful in identifying brain regions that are activated under many experimental conditions (for examples, see Morgan et al., 1987; Sagar et al., 1988; Dragunow and Faull, 1989). Expression of Fos is low under basal conditions but the protein is transiently induced in neural tissue (and in other tissues) in response to activation of specific intracellular messenger systems (Sheng and Greenberg, 1990).

There have been few studies comparing 2-DG uptake and Fos induction under the same experimental conditions. The limited data available in this regard suggest that distinct information may be obtained by utilizing each of these approaches. For example, in 2-DG studies examining effects of osmotic stress produced by salt loading, no increase in glucose utilization has been reported for the hypothalamic paraventricular nucleus (PVN) or supraoptic nucleus (Schwartz et al., 1979; Gross et al., 1985). In contrast, injection of hypertonic saline produces a robust induction of Fos in the PVN and supraoptic nucleus (Sagar et al., 1988; Sharp et al., 1991). Other experimental situations where assessment of 2-DG uptake and expression of Fos have yielded distinct information are after electrical stimulation of the motor cortex (Sagar et al., 1988; Sharp, 1989) and after the administration of $D_{1}$-dopamine agonists to 6-hydroxydopaminc-lcsioncd rats (Trugman and Wooten, 1987; Robertson et al., 1989; Trugman et al., 1991; Johnson et al., 1992).

Since 2-DG uptake and expression of Fos may provide distinct and complementary information, the present investigation compared neuroanatomical activation patterns with these two techniques in the forced swim test (Porsolt et al., 1978), a classic 
behavioral screen for antidepressant drug activity. There is currently no information available concerning brain regions activated in response to the swim test or for effects of antidepressant drug treatment on swim stress-induced alterations in brain activity patterns. The present investigation demonstrates highly selective neuroanatomical patterns of activation in response to swim stress and imipramine treatment and illustrates the utility of assessing both 2-DG uptake and Fos-like immunoreactivity (Fos-LI) to evaluate functional neuroanatomical correlates of behavior and drug action.

\section{Materials and Methods}

The forced swim test. The forced swim protocol described by Porsolt et al. (1978) was used for the present investigation. Rats were subjected to a 15 min conditioning swim in a cylindrical Plexiglas tank $(40 \mathrm{~cm}$ $\times 19 \mathrm{~cm})$ containing water $\left(25^{\circ} \mathrm{C}\right)$ at a depth of $16 \mathrm{~cm}$. Five minutes after the conditioning swim, rats were injected with $0.9 \%$ saline or imipramine $(25 \mathrm{mg} / \mathrm{kg})$, in volumes of $5 \mathrm{ml} / \mathrm{kg}$ body weight. The following day rats were injected with saline or drug solutions $1 \mathrm{hr}$ before being placed in the swim tanks for a 5 min test swim. The amount of time that the rats were immobile in the test swim was measured. In the forced swim test, immobility is induced in the test swim by previous exposure to the conditioning swim. Rats given antidepressant drugs exhibit less immobility and display more escape-directed behaviors in the test swim. In contrast to the behavioral activation by antidepressants under the stressful conditions of the forced swim test, these drugs decrease locomotor activity under basal conditions (Porsolt et al. 1978; Paul et al., 1990). Therefore, the behavioral activation by antidepressants in the forced swim test is not due to generalized locomotor stimulation.

High-resolution autoradiographic analysis of ${ }^{14} \mathrm{C}-2-D G$ uptake in response to swim stress. Details of the high-resolution autoradiographic procedures have been described in detail (Duncan and Stumpf, 1990; Duncan et al., 1990). Three to four days before the experiments, rats were implanted with chronic jugular catheters that were exteriorized at the base of the neck. Rats were brought from the animal quarters to the laboratory 4-5 $\mathrm{hr}$ before initiation of the 2-DG experiment. For the swim conditions, $1 \mathrm{hr}$ before the test swim, rats were injected intraperitoneally with saline $(n=5)$ or imipramine $(n=5)$ and returned to their home cage. Other groups of control rats (i.e., not swum) also were injected with saline $(n=5)$ or imipramine $(n=5)$. One hour after the saline or drug injections, rats were injected with ${ }^{14} \mathrm{C}$-2-DG (American Radiolabeled Chemicals; $0.5 \mu \mathrm{Ci} / \mathrm{gm}$ body weight) via the chronic jugular catheter. Rats in the swim condition were then immediately placed in the swim tanks and the control rats remained in their home cage. Rats were killed by decapitation $5 \mathrm{~min}$ after injection of ${ }^{14} \mathrm{C}-2-\mathrm{DG}$. Brains were frozen on an aluminum block cooled with liquid nitrogen and stored at $-80^{\circ} \mathrm{C}$ until sectioned. Ten-micrometer-thick cryostat sections of brains were thaw mounted onto pieces of Kodak Industrex SR-5 film that were glued to microscope slides. Sections mounted on the film were stored in desiccator boxes at room temperature for exposure. Radioactive standards $\left({ }^{14} \mathrm{C}\right.$-microscale, Amersham) were apposed to film mounted on slides in an x-ray cassette. After 3 months exposure, autoradiograms of sections and standards were developed in Kodak D-19 for $10 \mathrm{~min}$ at room temperature, washed in water for 10 sec, and fixed in Kodak General Purpose Fixer for $30 \mathrm{~min}$.

Quantitative analysis of 2-DG autoradiograms. Optical densities in autoradiograms were measured by digital image analysis with a videobased system from Imaging Research, Inc. (Ontario, Canada). Amounts of radioactivity in brain regions were derived by relating the optical density in brain regions to the those of the radioactive standards. Data are expressed as the ratio of radioactivity in gray matter regions relative to that in the corpus callosum.

Immunocytochemical assessment of Fos-LI in response to swim stress. Rats in the swim and control conditions were handled and weighed the day before the conditioning swim day. Control rats were injected with saline and returned to their home cages on the day preceding the perfusion and $2 \mathrm{hr}$ before the perfusion. For the swim condition, rats were injected with saline or imipramine and processed in the forced swim test as described above. Immunocytochemical procedures were performed as described by Johnson et al. (1992). Two hours after injection of saline or $2 \mathrm{hr}$ after the $5 \mathrm{~min}$ test swim, rats were anesthetized with

\section{Saline}

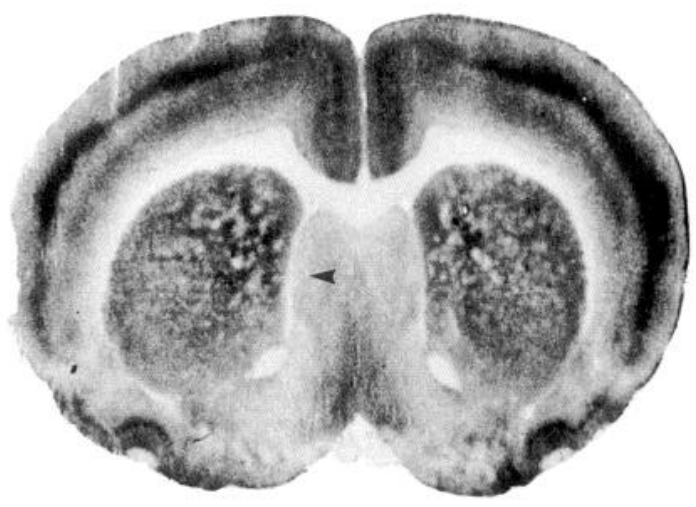

\section{Saline-Swim}

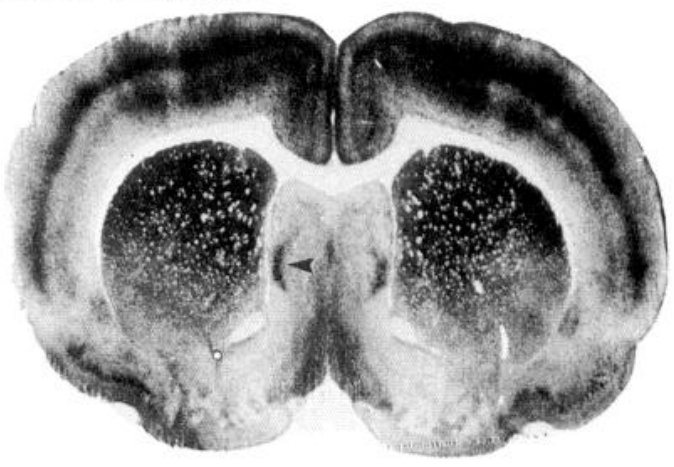

\section{Imipramine-Swim}

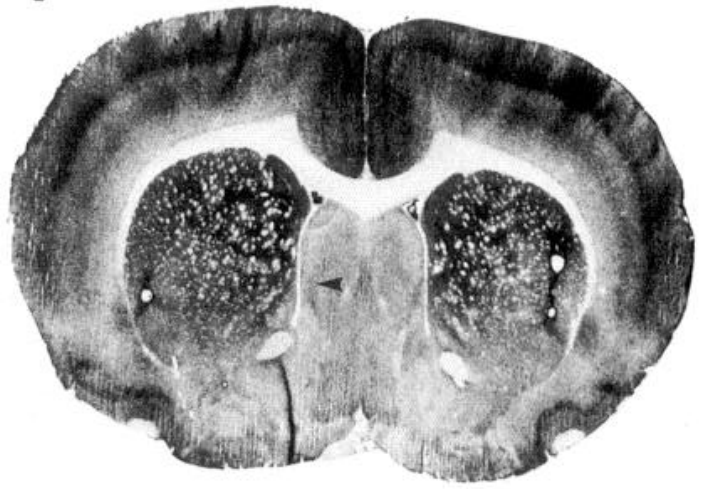

Figure 1. Activation of 2-DG uptake in the lateral septal nucleus in response to swim stress: photomicrographs of autoradiograms of 2-DG uptake. Note the low uptake of 2-DG in the lateral septum in the control rat $(A)$ and the high 2-DG uptake in the restricted arc-shaped region (arrowheads) of the lateral septum of the rat subjected to swim stress (B). Imipramine treatment antagonized the activation of 2-DG uptake in the lateral septum $(C)$.

$70 \mathrm{mg} / \mathrm{kg}$ Nembutal and perfused transcardially with ice-cold $100 \mathrm{~mm}$ sodium phosphate-buffered saline (PBS, pH 7.4), followed by $4 \%$ paraformaldehyde in PBS. Brains were postfixed in $4 \%$ paraformaldehyde overnight and $50 \mu \mathrm{m}$ vibratome sections were cut and placed in PBS contained in 24-well tissue culture dishes. Before application of the primary antibody, sections were treated with $10 \%$ normal rabbit serum and $0.2 \%$ Triton X-100 in PBS for $30 \mathrm{~min}$. Sections were then incubated for $48-72 \mathrm{hr}$ at $4^{\circ} \mathrm{C}$ with an affinity-purified sheep polyclonal Fos antiserum (1:10,000 or 1:5000 dilution) raised against a synthetic peptide corresponding to conserved regions of mouse and human Fos (Cambridge Research Biochemicals, Inc., Wilmington, DE). This antibody 

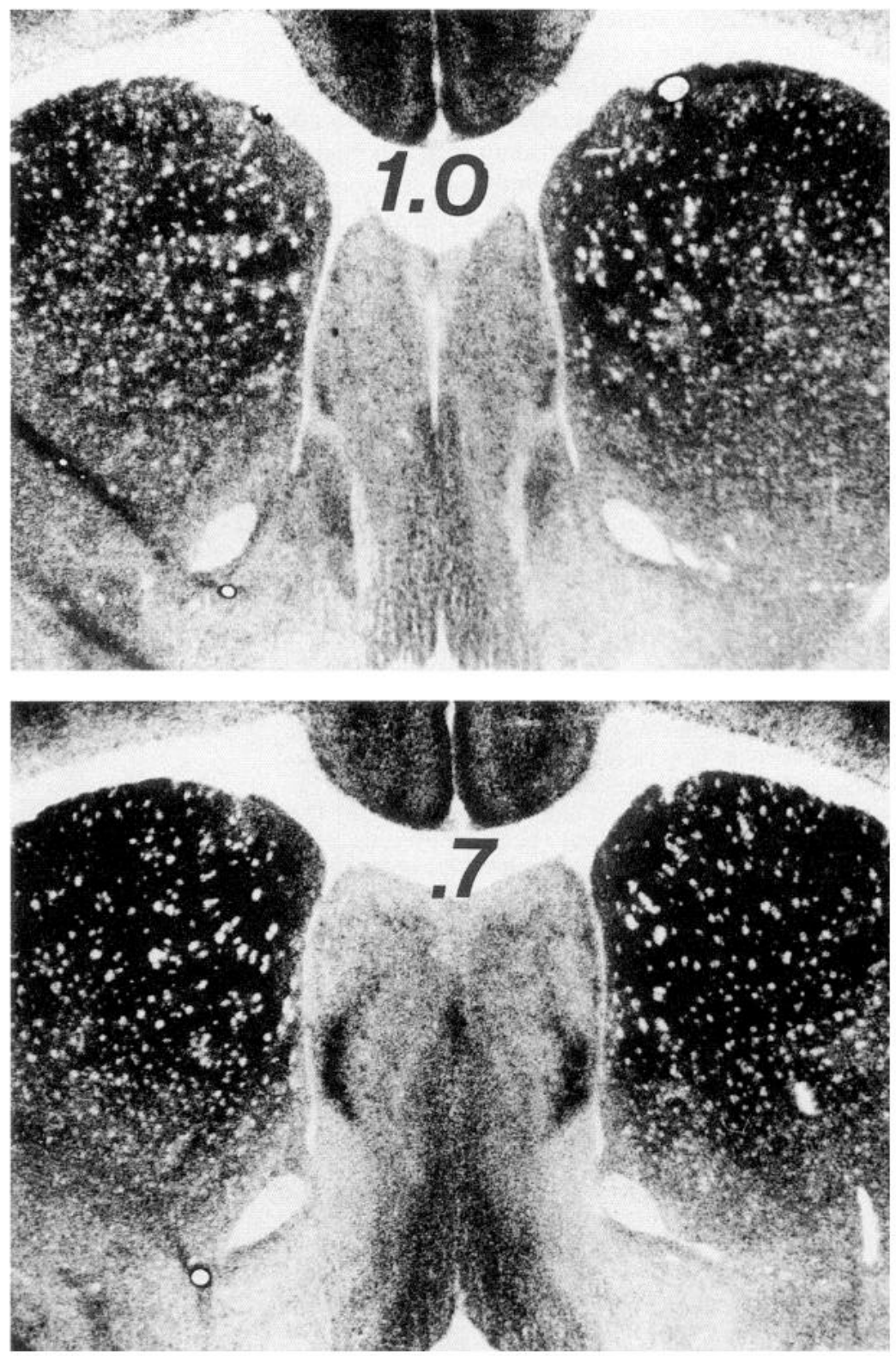

Figure 2. Limited rostral-caudal extent of swim stress-induced activation of the lateral septal nucleus: photomicrographs of autoradiograms through the lateral septum at three levels. Numbers on figures refer to approximate distances in millimeters from bregma from which the sections were taken.

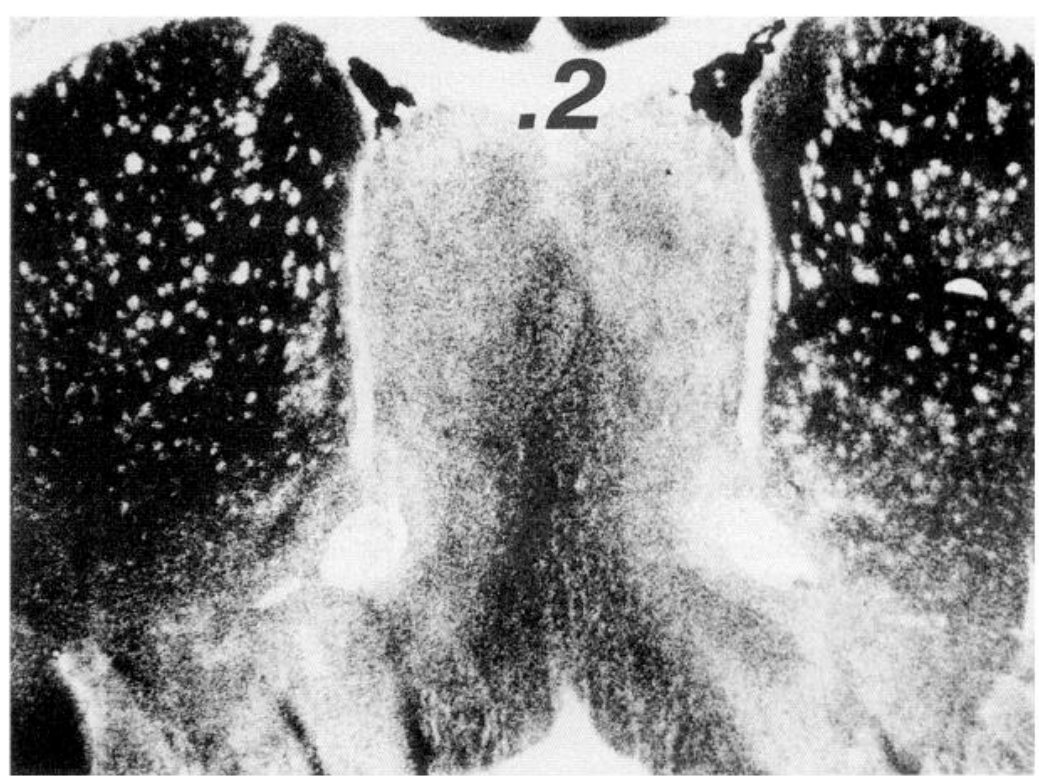



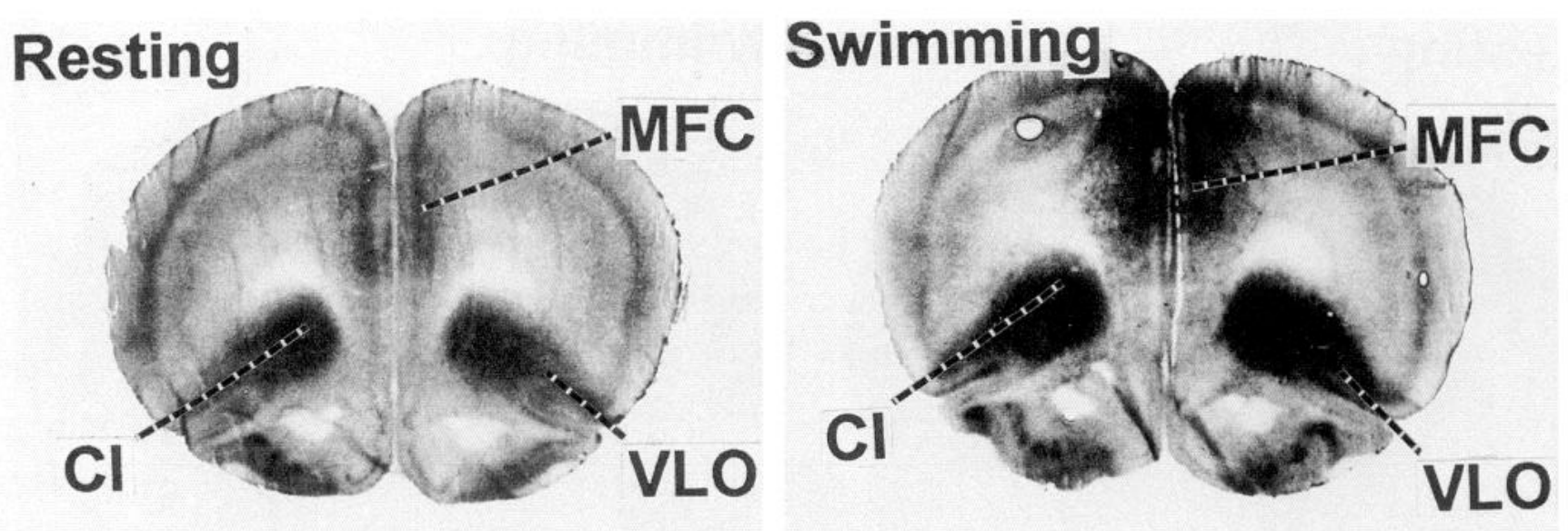

Figure 3. Swim stress-induced increase in 2-DG uptake in the medial prefrontal cortex $(M F C)$, ventrolateral orbital cortex (VLO), and claustrum $(C L)$.

may recognize Fos-related antigens as well as Fos. Therefore, data are described as Fos-like immunoreactivity. Sections were then rinsed in PBS and incubated for $1 \mathrm{hr}$ with biotinylated rabbit anti-goat antibody (Vector Laboratories, Burlingame, CA). After four rinses with PBS the sections were incubated with avidin-biotin complex (Vector Laboratories) for $1 \mathrm{hr}$. After an additional four rinses with PBS, sections were reacted with a solution containing $0.05 \% 3,3^{\prime}$-diaminobenzidine tetrahydrochloride, $0.01 \%$ cobalt chloride, $0.02 \%$ nickel ammonium sulfate, and $0.003 \%$ hydrogen peroxide. Cells exhibiting Fos-LI in select brain regions were counted at magnification of 100-200x.

Statistical analysis. Data were initially analyzed by two-way analysis of variance with repeated measures on one factor (brain region). Comparisons of individual brain regions between two groups were made by $t$ tests.

\section{Results}

Alterations in patterns of 2-DG uptake in response to swim stress. The behavior of rats in the test swim was characterized by 12 min of attempted climbing of the walls of the swim tank and occasional jumping from the floor of the tanks. This period of activity was followed primarily by floating in the water without vigorous escape-directed behavior. Selective and pronounced alterations in neuroanatomical patterns of 2-DG uptake were observed in the rats subjected to swim stress. Two-way ANOVA revealed a significant main effect of swim and a significant swim $\times$ region interaction $(p<0.01)$ for relative $2-D G$ uptake in regions examined (Table 1). The most pronounced increase in relative 2 -DG uptake in response to swim stress occurred in a restricted region of the lateral septal nucleus (Figs. 1, 2). Relatively low uptake of 2-DG was observed in the lateral septum under basal conditions. In swim-stressed rats, a discrete arcshaped region of the lateral septum exhibited a dramatic increase in 2-DG uptake. The rostral-caudal extent of the activated region was less than $1 \mathrm{~mm}$, as illustrated in Figure 2. The precise arc-shaped pattern and limited rostral-caudal extent of the activated region of the lateral septum was observed consistently in all rats in the saline-swim condition. In addition to the lateral septal nucleus, increased 2-DG uptake was observed in response to swim stress in the medial prefrontal cortex, ventrolateral orbital cortex, claustrum (Fig. 3), cingulate cortex, and motor cortex (Table 1). No change in relative 2-DG uptake was apparent in response to swim stress in the PVN (Fig. 4) or in other brain regions examined (Table 1).

Expression of Fos-LI in response to swim stress. Under the control conditions of the present study, isolated cells expressing
Fos-LI were observed scattered in many brain regions. A few regions were notable for containing a slightly greater frequency of cells expressing Fos-LI compared to other regions in the control rats. These regions were the piriform cortex, paraventricular nucleus of the thalamus, lateral septal nucleus, medial prefrontal cortex, and widespread regions of the hypothalamus. Within the hypothalamus, the anterior hypothalamic area, dorsal medial nucleus, and zona inserta exhibited the greatest number of Fos-positive cells. Cells expressing Fos-LI were rarely observed in the PVN of saline-injected rats.

For saline-treated rats processed in the forced swim test, several select brain regions contained many more cells positive for Fos-LI when compared to rats in the saline-home cage condition (Table 2). These regions were the lateral septal nucleus (Figs. 5, 6 ), medial prefrontal cortex, ventrolateral orbital cortex, claustrum (Fig. 7), and PVN (Fig. 8). In the PVN, the most prominent expression of Fos-LI occurred in the parvocellular division. However, in some rats in the swim condition, cells in the magnocellular component of the PVN also exhibited Fos-LI. Cells exhibiting Fos-LI were observed in the motor and parietal cortices in some, but not in all rats, in the swim condition.

Comparison of alterations in 2-DG uptake and induction of Fos in response to swim stress. For some brain regions, changes in both 2-DG uptake and induction of Fos-LI were observed in response to swim stress. However, in certain brain regions, distinctly different information was obtained by the two approaches. In the lateral septum, the rostral-caudal extent and topographic distribution of the cells containing Fos-LI were similar to the region in which swim stress activated 2-DG uptake (compare Figs. 2,6). The claustrum and specific cortical regions (medial prefrontal, ventrolateral orbital, and cingulate) also exhibited both increased relative 2 -DG uptake and an increase in the number of cells exhibiting Fos-LI in response to swim stress. However, in the PVN, a marked induction of Fos-LI was observed, but no increase in 2-DG uptake was found in the swimstressed rats. Conversely, in layer 6 of the motor cortex and in regions of the parietal cortex, swim stress was associated with increased 2-DG uptake but induction of Fos-LI was not consistently observed.

Effects of imipramine treatment on 2-DG uptake and induction of Fos-LI under basal and swim stress conditions. After imipramine treatment under basal conditions, the only brain region where relative $2-\mathrm{DG}$ uptake was altered was the medial 


\section{Resting}

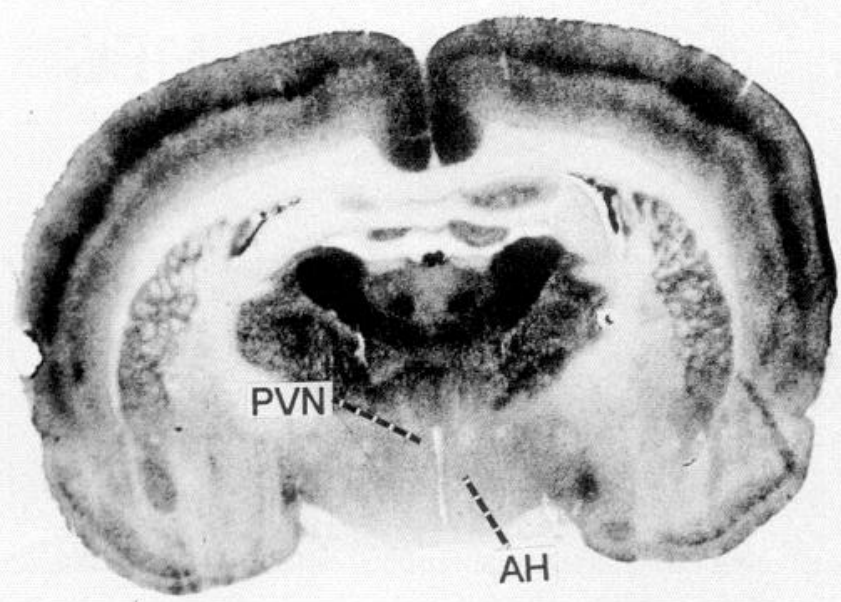

\section{Swimming}

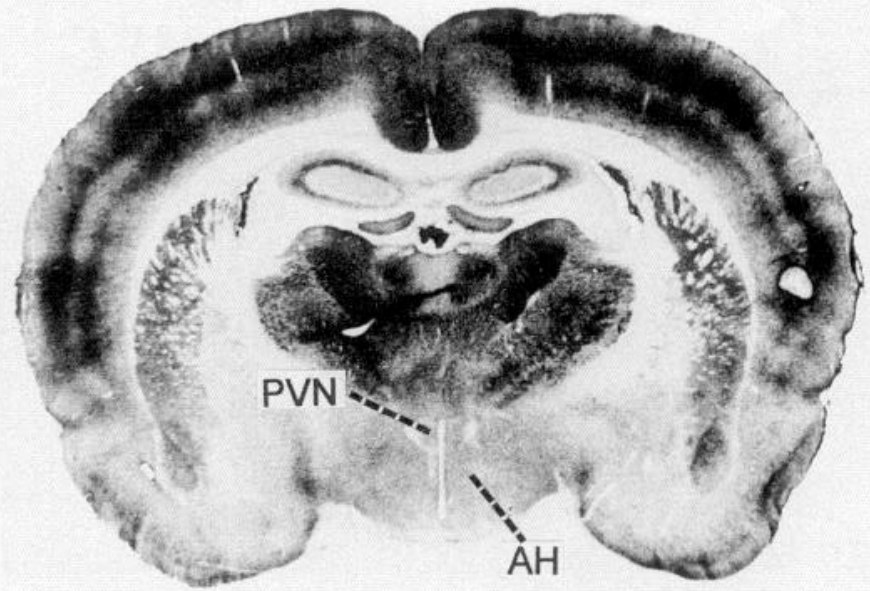

Figure 4. Lack of alteration in 2-DG uptake in the PVN in response to swim stress. $A H$, anterior hypothalamic area.

septal nucleus, where decreased uptake of the compound was observed (Table 1). However, imipramine treatment induced a robust induction of Fos-LI in two specific brain regions-the dorsal lateral component of the bed nucleus of the stria terminalis and the central nucleus of the amygdala (Fig. 9). In the central nucleus of the amygdala, the highest densities of labeled cells were observed in more caudal aspects of the nucleus.

Rats treated with imipramine and processed in the forced swim test exhibited less immobility time (i.e., were more active) compared to rats injected with saline (immobility times, mean seconds \pm SEM: saline, $212 \pm 13$; imipramine, $123 \pm 9 ; p<$ $0.01)$. Imipramine treatment antagonized the stress-induced activation of 2-DG uptake in the arc-shaped region of the lateral septal nucleus. (Fig. 1, Table 1). In addition, the 2-DG uptake in the medial septal nucleus was reduced in the imipramineswim compared to the saline-swim condition. There was no
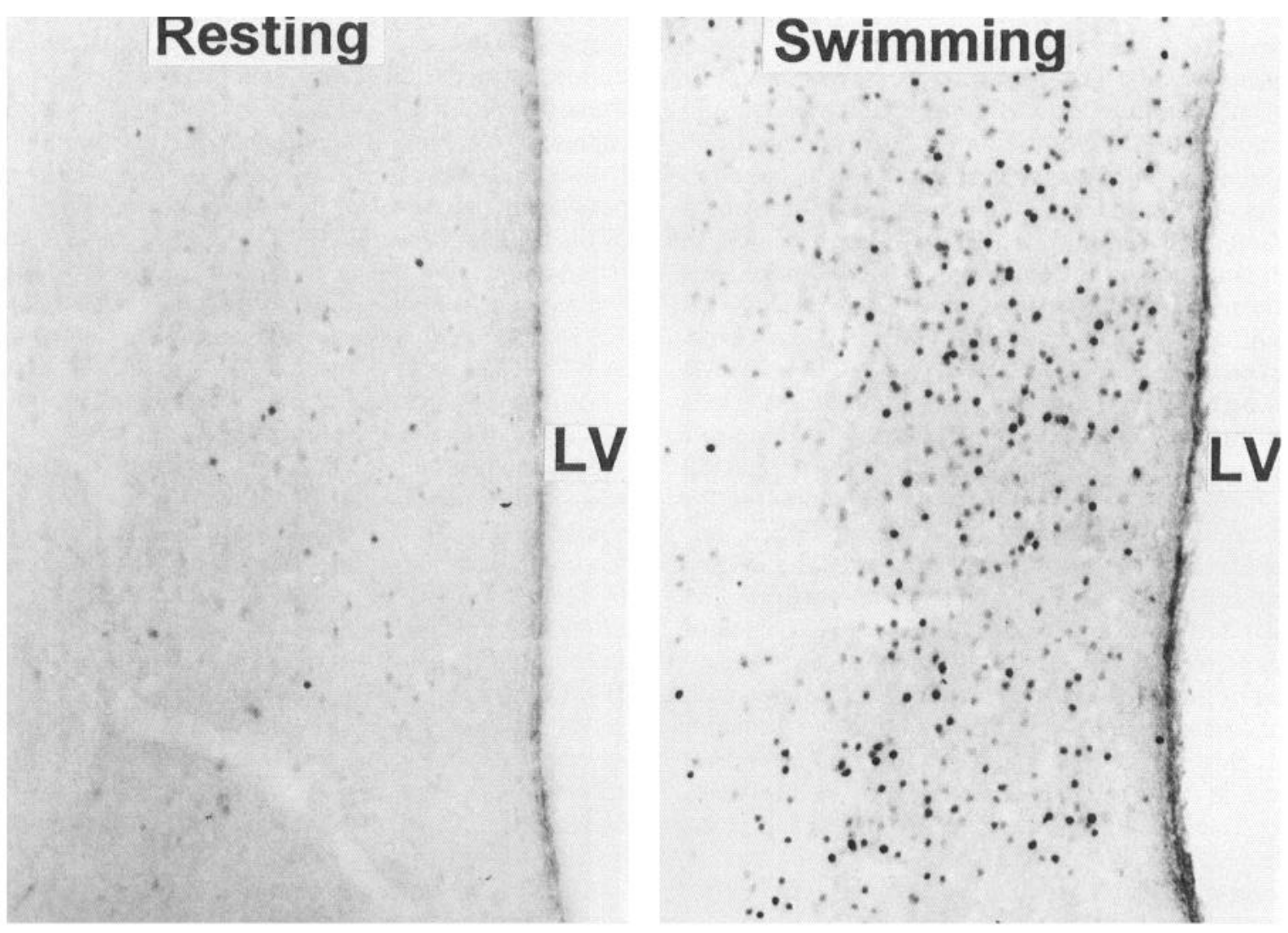

Figure 5. Induction of Fos-LI in the lateral septal nucleus by swim stress: photomicrographs of immunocytochemically stained sections through the lateral septum. $A$, control; $B$, swim stress. $L V$, lateral ventricle. 
Table 1. Relative 2-DG uptake in response to swim stress and imipramine

\begin{tabular}{lllll} 
& Saline & Saline-swim & Imipramine & Impramine-swim \\
\hline Medical prefrontal cortex & $2.06 \pm 0.06$ & $2.45 \pm 0.02^{*}$ & $1.93 \pm 0.05$ & $2.56 \pm 0.09$ \\
Claustraum & $2.20 \pm 0.11$ & $2.62 \pm 0.07^{*}$ & $1.85 \pm 0.09$ & $2.66 \pm 0.08$ \\
Ventrolateral orbital cortex & $2.07 \pm 0.08$ & $2.52 \pm 0.06^{*}$ & $2.15 \pm 0.07$ & $2.43 \pm 0.07$ \\
Cingulate cortex & $1.73 \pm 0.06$ & $2.03 \pm 0.08^{*}$ & $1.86 \pm 0.03$ & $1.98 \pm 0.12$ \\
Motor cortex (layer 6) & $1.68 \pm 0.09$ & $2.10 \pm 0.09^{*}$ & $1.70 \pm 0.05$ & $1.82 \pm 0.09$ \\
Lateral septum, ventral & $1.55 \pm 0.06$ & $1.92 \pm 0.09^{*}$ & $1.36 \pm 0.06$ & $1.44 \pm 0.07^{* *}$ \\
Lateral septum, dorsal & $1.41 \pm 0.09$ & $1.41 \pm 0.06$ & $1.33 \pm 0.03$ & $1.30 \pm 0.06$ \\
Medial septum/diagonal band & $1.86 \pm 0.05$ & $1.94 \pm 0.08$ & $1.60 \pm 0.04^{*}$ & $1.56 \pm 0.11^{* *}$ \\
Paraventricular nuclcus, & & & & \\
$\quad$ magnocellular & $1.25 \pm 0.06$ & $1.22 \pm 0.04$ & $1.22 \pm 0.01$ & $1.11 \pm 0.02$ \\
Paraventricular nucleus, & & & & \\
$\quad$ paravocellular & $1.37 \pm 0.08$ & $1.30 \pm 0.05$ & $1.20 \pm 0.02$ & $1.37 \pm 0.05$ \\
Anterior hypothalamic area & $1.34 \pm 0.05$ & $1.31 \pm 0.07$ & $1.24 \pm 0.02$ & $1.41 \pm 0.05$ \\
$\begin{array}{l}\text { Dentate gyrus, molecular layer } \\
\text { Hippocampus, CA1 }\end{array}$ & $1.50 \pm 0.11$ & $1.56 \pm 0.03$ & $1.49 \pm 0.03$ & $1.61 \pm 0.07$ \\
$\quad$ stratum radiatum & $1.25 \pm 0.04$ & $1.33 \pm 0.05$ & $1.10 \pm 0.04$ & $1.31 \pm 0.04$ \\
Hippocampus, CA3 & & & & \\
$\quad$ stratum radiatum & $1.32 \pm 0.04$ & $1.21 \pm 0.06$ & $1.22 \pm 0.03$ & $1.34 \pm 0.03$ \\
Amygdala, basolateral & $1.53 \pm 0.08$ & $1.63 \pm 0.13$ & $1.44 \pm 0.03$ & $1.61 \pm 0.03$ \\
Amygdala, central & $1.12 \pm 0.05$ & $0.97 \pm 0.06$ & $1.03 \pm 0.01$ & $1.11 \pm 0.02$ \\
Lateral hypothalamic area & $1.24 \pm 0.01$ & $1.26 \pm 0.03$ & $1.25 \pm 0.03$ & $1.35 \pm 0.03$ \\
Lateral habenula & $2.08 \pm 0.11$ & $2.12 \pm 0.14$ & $1.88 \pm 0.07$ & $2.10 \pm 0.03$ \\
& & & & \\
\hline
\end{tabular}

Data are mean \pm SEM and are expressed as ratios of radioactivity in gray matter regions relative to that in the corpus callosum.

* Significantly different compared to saline, $p<0.05$.

** Significantly different compared to saline-swim, $p<0.05$.

apparent difference in relative $2-D G$ uptake between the imipramine-swim and saline-swim groups in other brain regions examined. Induction of Fos-LI by swim stress in the lateral septum, PVN, and cortical regions was not altered by administration of imipramine (Table 2).

\section{Discussion}

The autoradiographic analysis of 2-DG uptake and immunohistochemical assessment of Fos-LI of the present investigation provide insights into functional neuroanatomical responses to stress. Select cortical regions and a restricted region of the lateral septum were identified in both 2-DG and Fos-LI induction studies that may represent previously unrecognized components of neural circuitry activated by swim stress. For some brain regions, 2-DG uptake and Fos-LI provided distinct and complementary information concerning brain activity patterns associated with swim stress and responses to imipramine. The different perspective of neuroanatomically selective functional activation provided by $2-$ DG uptake and Fos-LI demonstrates the utility of applying both approaches to the same experimental setting.

The classic stress response involves increased secretion of glucocorticoid hormones from the adrenal gland. Neurons whose cell bodies are located in the parvocellular division of the PVN secrete corticotropin-releasing hormone (CRH) into the hypophyseal portal system and thereby control the release of adrenocorticotrophic hormone (ACTH) from the pituitary (Bloom et al., 1982; Merchenthaler et al., 1982; Rivier et al., 1982).

Table 2. Counts of cells exhibiting Fos-LI in response to swim stress

\begin{tabular}{lccll} 
& Saline & Imipramine & Swim & Impramine-swim \\
\hline Medial prefrontal cortex & $10 \pm 2$ & $8 \pm 3$ & $33 \pm 6^{*}$ & $31 \pm 4$ \\
Claustrum & $2 \pm 1$ & $<1$ & $25 \pm 5^{*}$ & $16 \pm 7$ \\
Ventrolateral orbital cortex & $<1$ & $6 \pm 5$ & $20 \pm 8^{*}$ & $13 \pm 5$ \\
Lateral septal nucleus & $21 \pm 8$ & $31 \pm 11$ & $81 \pm 13^{*}$ & $97 \pm 16$ \\
Cingulate cortex & $2 \pm 1$ & $<1$ & $32 \pm 5^{*}$ & $23 \pm 5$ \\
Paraventricular nucleus & & & & \\
$\quad$ of the hypothalamus & $3 \pm 1$ & $6 \pm 3$ & $70 \pm 8^{*}$ & $65 \pm 7$ \\
Anterior hypothalamic area & $10 \pm 3$ & $12 \pm 1$ & $8 \pm 2$ & $12 \pm 2$
\end{tabular}

Data are mean \pm SEM and are expressed as number of cells $/ \mathrm{mm}^{2}$ except for the lateral septal nucleus and the paraventricular nucleus. For the lateral septal nucleus, data are mean number of cells per section in the arc-shaped region adjacent to the lateral ventricle as illustrated in Figure 5 . For the paraventricular nucleus, data are mean number of cells per section in the parvocellular and magnocellular subdivisions.

* Significantly different from saline, $p<0.01$. 

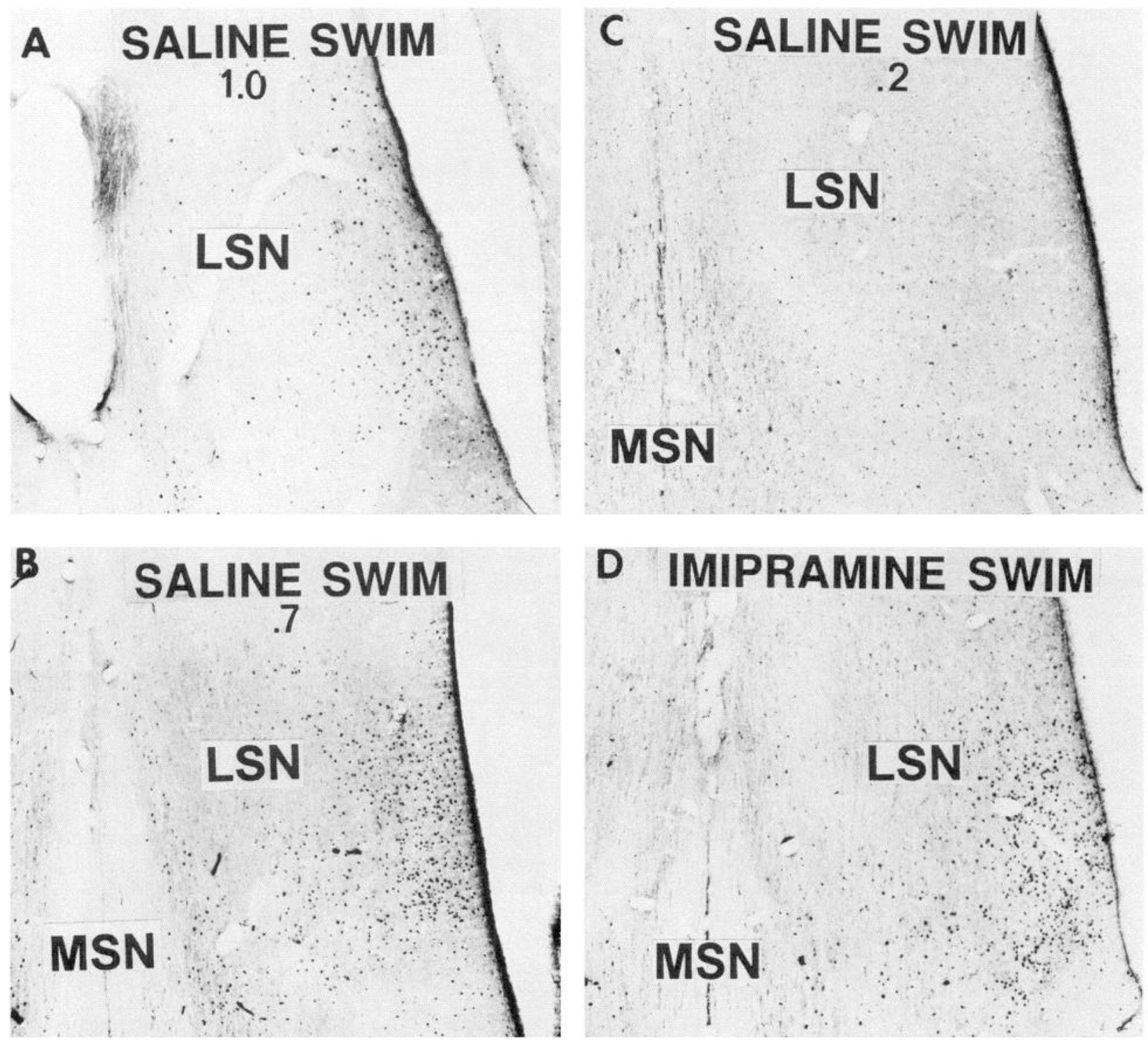

Figure 6. Induction of Fos-LI at different levels of the lateral septum and lack of effect of imipramine treatment: photomicrographs of immunocytochemically stained sections through the lateral septum. Sections presented in $A-C$ represent progressively more caudal levels, and numbers refer to approximate distance in millimeters anterior to bregma. $D$, Immunocytochemically stained section from a rat treated with imipramine and processed in the forced swim test. $M S N$, medial septal nucleus; $L S N$, lateral septal nucleus.

Rats processed in the forced swim test exhibit marked increases in plasma corticosterone levels (Paul et al., 1990), indicating physiological activation of CRH-containing neurons in the PVN. Thus, it was expected that functional activation of the PVN in response to swim stress would be reflected by increased 2-DG uptake and expression of Fos-LI in this hypothalamic region. While swim stress induced a marked increase in cells exhibiting Fos-LI in the PVN, there was no apparent change in 2-DG uptake in the PVN in response to swim stress. In previous studies that have examined effects of stress on regional glucose utilization (Bryan et al., 1983; Caldecott-Hazard et al., 1988; Justice et al., 1989), only the study of Justice et al. (1989) reported an increase of 2-DG uptake in the PVN. However, a variety of stressors have previously been demonstrated to induce Fos in the PVN (Ceccatelli et al., 1989; Chastrette et al., 1991; Sharp et al., 1991). Thus, the present work and previous studies suggest that, for neurons in the PVN, expression of FosLI is a better indicator of functional activity than 2-DG uptake.

In contrast to the PVN, several other brain regions exhibited both increased 2-DG uptake and expression of Fos-LI in response to swim stress. A prominent induction of Fos-LI and increase in 2-DG uptake were observed in an arc-shaped region of lateral septal nucleus. The subregion of the lateral septal nucleus activated by swim stress does not correspond entirely to any presently recognized subdivision, based on general cytoarcitecture. However, the topography of $\mathrm{CRH}$ innervation of the lateral septum (Sakanaka et al., 1988) is similar to the activation pattern observed in response to swim stress. The fibers and terminals in the lateral septum that exhibit CRH-like immunoreactivity represent projections from $\mathrm{CRH}$-containing neurons located in the anterior hypothalamic area (Sadanaka et al., 1988). The CRH-containing neurons in the anterior hypo- 


\section{Resting \\ MFC}

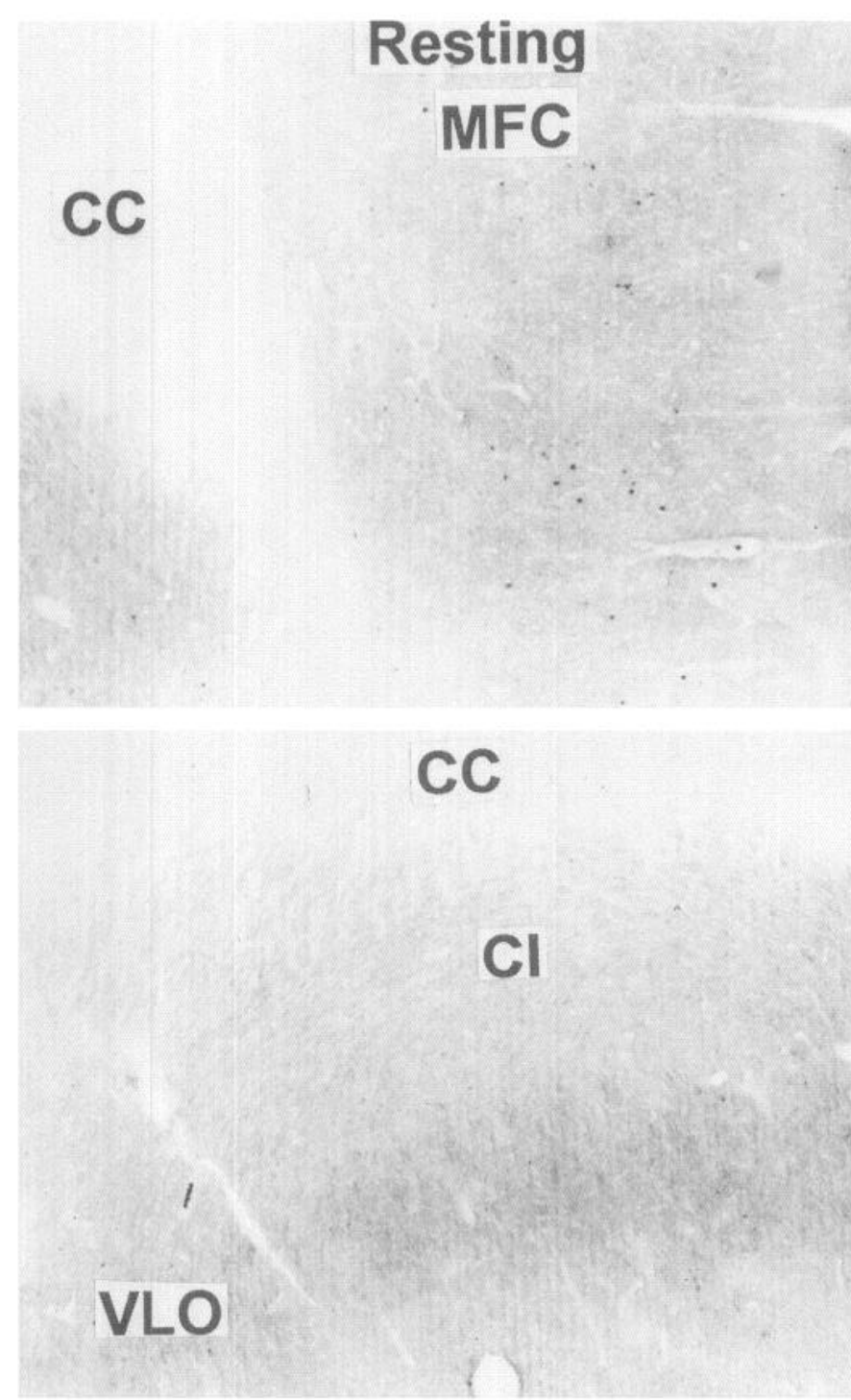

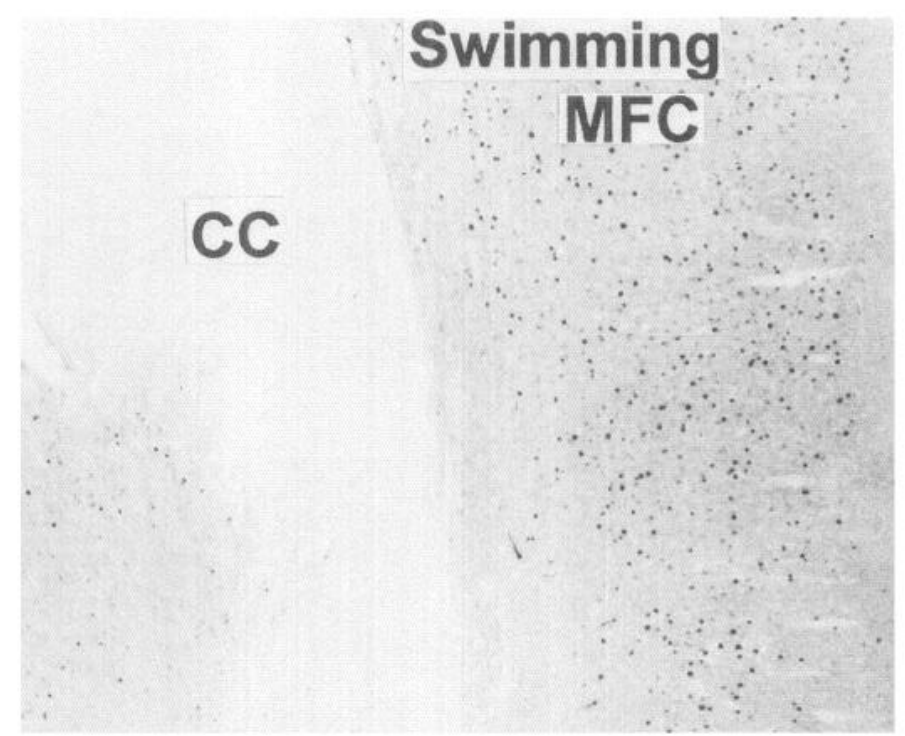

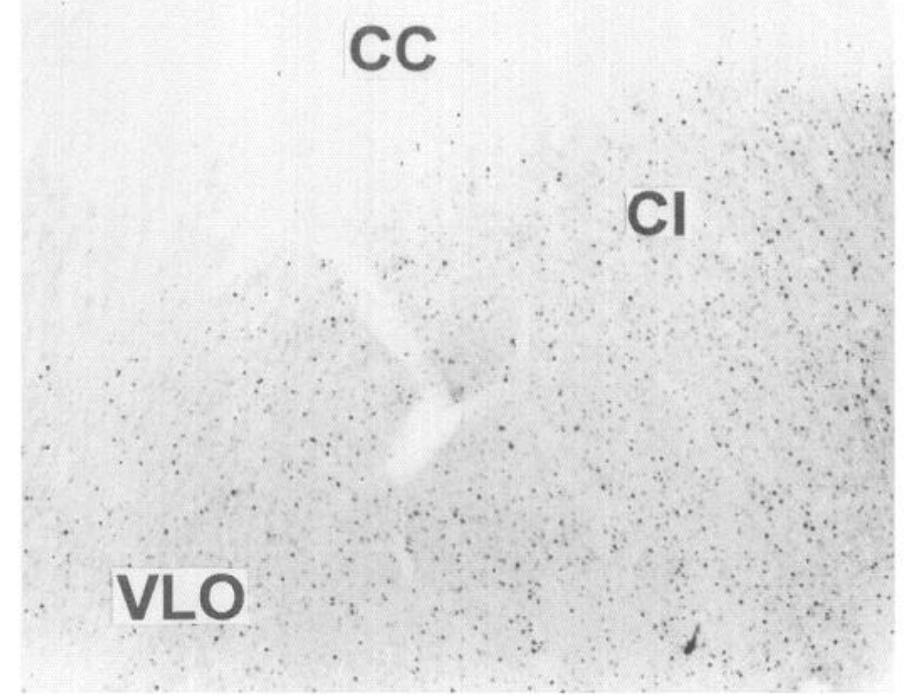

Figure 7. Induction of Fos-LI by swim stress in the medial prefrontal cortex $(M F C)$, claustrum $(C L)$, and ventrolateral orbital cortex $(V L O)$ : photomicrographs of immunocytochemically stained sections from resting (left panels) and swim-stressed (right panels) rats. CC, corpus callosum.

thalamic area are apparently not involved in regulation of ACTH secretion (Sakanaka et al., 1988). It is possible that the observed stress-induced activation of 2-DG uptake and expression of Fos$\mathrm{LI}$ in the lateral septum may involve the CRH pathway from the anterior hypothalamic area to the septum. However, in swimstressed rats, compared to controls, no increase in 2-DG uptake or Fos-LI was apparent in the anterior hypothalamic area. Therefore, a potential functional relationship between $\mathrm{CRH}$ containing neurons in the anterior hypothalamic area and activation of the lateral septum by swim stress is provocative, but remains to be established.

In addition to the lateral septal nucleus, the claustrum and specific cortical regions-medial prefrontal, ventrolateral orbital, and cingulate cortices-exhibited both increased 2-DG uptake and expression of Fos-LI in response to swim stress. The medial prefrontal cortex has previously been implicated in stress responses. Dopamine turnover is increased preferentially in this region after isolation and footshock stress (Thierry et al., 1976; Lavielle et al., 1978; Herve et al., 1979; Blanc et al., 1980). To our knowledge, the present data provide the first demonstration that the claustrum, ventrolateral orbital cortex, and cingulate cortex are activated by stress. The cortical regions exhibiting stress-induced increases in 2-DG uptake and expression of Fos$\mathrm{LI}$ are associated with the limbic system, as defined by Swanson (1983). Except for the lateral septum, other "limbic structures," including the hippocampus and amygdala, did not express Fos$\mathrm{LI}$ in response to swim stress.

Previous studies investigating the effects of other stressors on induction of Fos and 2-DG uptake have not described identical neuroanatomical patterns of activation as found in the present investigation. Sharp et al. (1991) found that injection of isotonic saline induced Fos mRNA in widespread regions of the forebrain. It is possible that the sparse densities of cells exhibiting Fos-LI in the present study in the medial prefrontal cortex, lateral septal nucleus, and select cortical regions were due to the slight stress of the saline injection. Ceccatelli et al. (1989) examined the effects of immobilization stress and nociceptive activation by subcutaneous capsaicin injection on induction of 

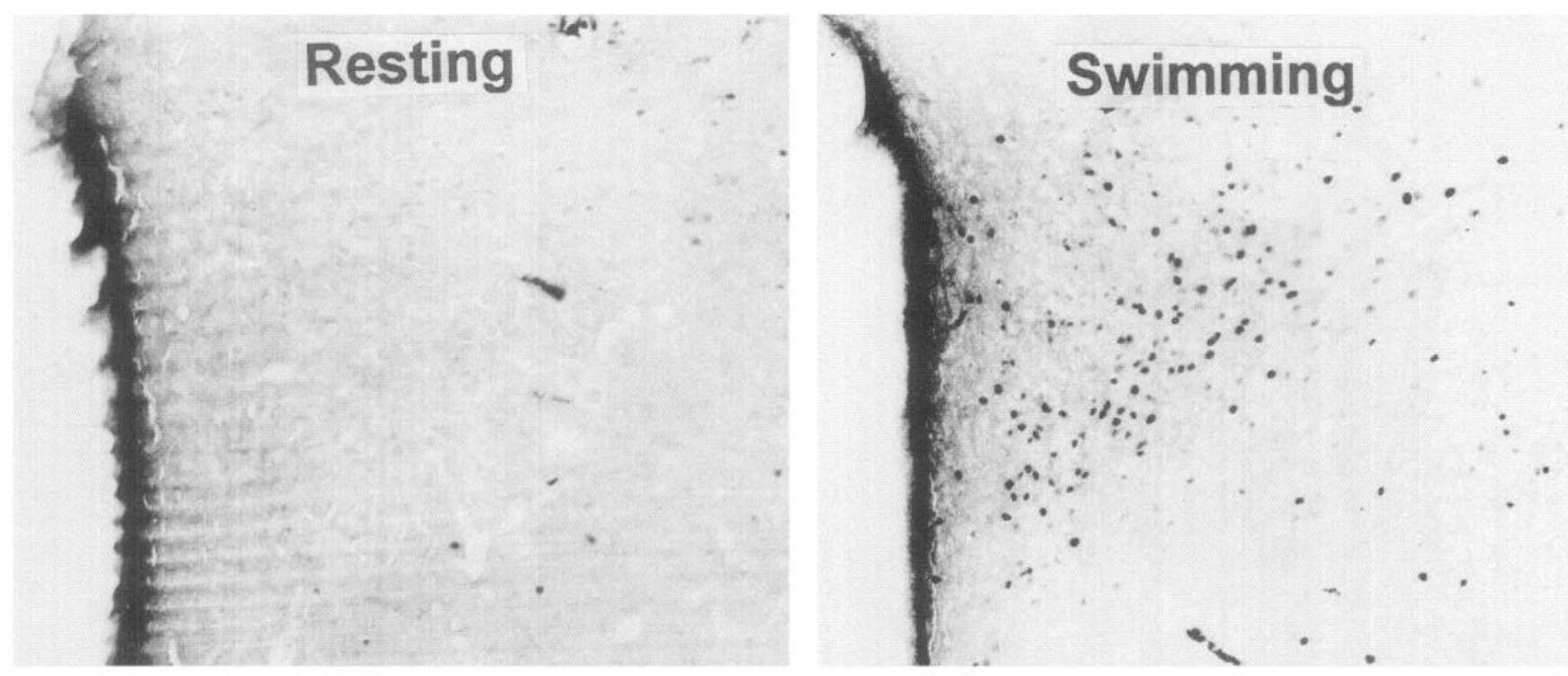

Figure 8. Induction of Fos-LI by swim stress in the PVN: immunocytochemically stained sections from a resting (left) and swim-stressed (right) rats.

Fos-LI. These stressors induced Fos-LI in the PVN and in the locus coeruleus and also in catecholamine-containing neurons in the medulla oblongata. Honkaniemi et al. (1992) found that injection of capsaicin resulted in induction of c-fos mRNA in the central nucleus of the amygdala and the PVN. Campeau et al. (1991) also found that foot shock induced c-fos mRNA in the amygdala. Pezzone et al. (1992) observed Fos-LI in the PVN, lateral septum, and medial but not central nucleus of the amygdala after unconditioned and conditioned aversive stimuli. Arnold et al. (1992) investigated the effects of immobilization stress and observed induction of Fos-LI in the PVN and lateral septum but not in any region of the amygdala. Rats processed in the forced swim test showed induction of Fos-LI in the PVN and lateral septal nucleus but did not exhibit Fos-positive cells in the locus coeruleus (G. E. Duncan, K. B. Johnson, and G. R. Breese, unpublished observations) or in any regions of the amygdala. Chastrette et al. (1991) found that immobilization stress induced Fos-LI in the PVN and the lateral habenula. A previous 2-DG study also found that chronic stress was associated with increased glucose utilization in the lateral habenula and that this stress-induced activation was antagonized by the antidepressant tranylcypromine (Caldecott-Hazard et al., 1988). In the present study, swim stress was not associated with increased 2-DG uptake in the lateral habenula and did not induce Fos-LI in this region. The data from the various studies reviewed above suggest that different types of stressors influence distinct brain regions.

The specific swim stress paradigm used in the present investigation, the forced swim test, is a behavioral pharmacological screen for antidepressant drugs. In the forced swim test, administration of a wide variety of antidepressant drugs antagonizes the immobility in a test swim that is induced by previous exposure to swim (Porsolt et al., 1978). The antidepressant drug imipramine was administered in the present investigation to determine if there were functional neuroanatomical correlates to the behavioral effects of the drug in the forced swim test. The induction of Fos-LI in the lateral septal nucleus by swim stress was not altered by imipramine treatment. However, imipramine blocked the stress-induced activation of 2-DG uptake in the lateral septum. These observations suggest that induction of Fos is controlled by different mechanisms than those responsible for activation of 2-DG uptake. Antagonism of the stress-induced increase in 2-DG uptake in the lateral septum by imipramine, even though the drug-treated rats were more active, indicates that the activation of this region by swim stress is not related to motor activity. The potential role of motor activity in the induction of Fos-LI observed in other regions in the present investigation will require further study.

Considerable experimental data have implicated the amygdala in the actions of antidepressant drugs (Gorka et al., 1979; Broekkamp et al., 1982; Araki et al., 1984; Duncan et al., 1986, 1989; Ordway et al., 1991). In the present study, treatment with imipramine induced a robust induction of Fos-LI in the central nucleus of the amygdala. There was also a robust induction of Fos-LI by imipramine in the lateral part of the dorsal division of the bed nucleus of the stria terminalis. The central nucleus of the amygdala projects to the region of the bed nucleus of the stria terminalis in which Fos-LI was induced (Krettek and Price, 1978). Therefore, it is possible that a functional relationship exists for effects of the imipramine in these two regions. In the bed nucleus of the stria terminalis, and in the central nucleus of the amygdala, there were no differences between the imipramine-home cage and imipramine-swim groups with respect to induction of Fos-LI. In contrast to the marked induction of Fos-LI in specific regions by imipramine, relative 2-DG uptake was not altered in these regions by imipramine treatment.

The differences observed in 2-DG uptake and expression of Fos-LI in response to swim stress and imipramine treatment are likely due to markedly different aspects of cellular physiology that are measured by the two approaches. It has been proposed that changes in 2-DG uptake reflect altered glucose utilization associated with the regulation of ionic gradients between intracellular and extracellular compartments of neural tissue (Mata et al., 1980; Astrup et al., 1981; Kadekaro et al., 1987). Most of the volume of brain tissue is composed of neuropil. Studies of ${ }^{3} \mathrm{H}-2-\mathrm{DG}$ uptake at the cellular level have shown that for most brain regions, the accumulation of radioactivity per unit area of neuropil and neuronal cell bodies is similar (Duncan et 
The Journal of Neuroscience, September 1993, 13(9) 3941
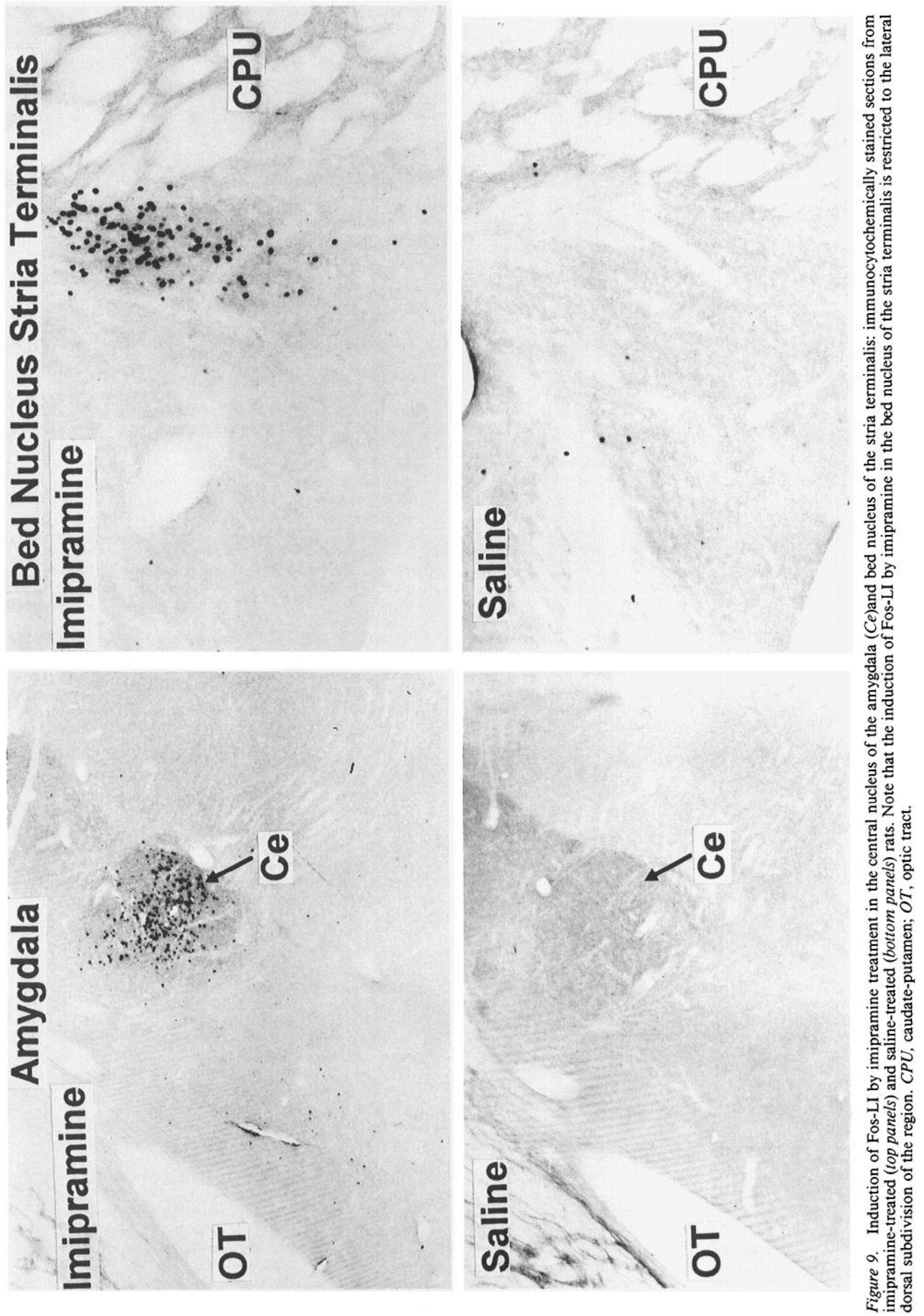
al., 1987, 1990; Duncan and Stumpf, 1991). Therefore, at the regional topographic level, the vast majority of 2-DG uptake observed in autoradiograms reflects the uptake of the compound in nerve terminals and other neuronal and glial processes that compose neuropil. In contrast, Fos is expressed in the cell bodies of ncurons that are activated by mechanisms that produce increased intracellular levels of calcium or cAMP (for review, see Sheng and Greenberg, 1990). Consequently, induction of Fos permits localization of individual cell bodies that have been activated by processes that involve specific signal transduction mechanisms. The results of the present investigation illustrate the utility of assessing both 2-DG uptake and Fos-LI to examine functional neuroanatomical correlates of behavior and drug actions.

\section{References}

Anisman H, Zacharko RM (1982) Depression: the predisposing influence of stress. Behav Brain Sci 5:89-137.

Araki H, Kawashima K, Aihara H (1984) The difference in the site of actions of tricyclic antidepressants and methamphetamine on the duration of the immobility in the behavioral despair test. Jpn J Pharmacol 35:67-72.

Arnold FJL, de Lucas Bueno M, Shiers H, Hancock DC, Evan GI, Herbert J (1992) Expression of c-fos in regions of the basal limbic forebrain following intracerebroventricular corticotropin-releasing factor in unstressed or stressed male rats. Neuroscience 51:377-390.

Astrup J, Sorensen PM, Sorensen HR (1981) Oxygen and glucose consumption related to $\mathrm{Na}^{+}-\mathrm{K}^{+}$transport in canine brain. Stroke 12: 726-730.

Blanc G, Herve D, Simon H, Lisoprawski A, Glowinski J, Tassin JP (1980) Response to stress of mesocortico-frontal dopaminergic neurones in rats after long-term isolation. Nature 284:265-267.

Bloom FE, Battenberg ELF, Rivier J, Vale E (1982) Corticotropinreleasing factor (CRF) immunoreactive neurons and fibers in rat hypothalamus. Regul Peptides 4:43-48.

Broekkamp CL, Garrigou D, Lloyd KG (1982) The importance of the amygdala in the effect of antidepressants on olfactory bulbectomised rats. In: Advances in biochemical psychopharmacology, Vol 31 (Costa E, Racagni G, eds), pp 371-377. New York: Raven.

Bryan RM, Hawkins RA, Mans AM, Davis DW, Page RB (1983) Cerebral glucose utilization in awake unstressed rats. Am Physiol Soc 244:C270-C275.

Caldecott-Hazard S, Mazziotta J, Phelps M (1988) Cerebral correlates of depressed behavior in rats visualized using ${ }^{14} \mathrm{C}$-2-deoxyglucose autoradiography. J Neurosci 8:1951-1961.

Campeau S, Hayward MD, Hope BT, Rosen JB, Nestler EJ, Davis M (1991) Induction of c-fos proto-oncogene in rat amygdala during unconditioned and conditioned fear. Brain Res 565:349-352.

Ceccatelli S, Villar MJ, Goldstein M, Hokfelt T (1989) Expression of c-fos immunoreactivity in transmitter-characterized neurons after stress. Proc Natl Acad Sci USA 86:9569-9573.

Chastrette N, PfaffEW, Gibbs RB (1991) Effects of daytime and nighttime stress on Fos-like immunoreactivity in the paraventricular nucleus of the hypothalamus, the habenula, and the posterior paraventricular nucleus of the thalamus. Brain Res 563:339-344.

Dragunow M, Faull R (1989) The use of $c$ - fos as a metabolic marker in the neuronal pathway tracing. J Neurosci Methods 29:261-265.

Duncan GE, Stumpf WE (1990) High resolution autoradiographic imaging of brain activity patterns with radiolabeled 2-deoxyglucose. In: Methods in neurosciences, Vol 3 (Conn PM, ed), pp 50-64. New York: Academic.

Duncan GE, Stumpf WE (1991) Brain activity patterns: assessment by high resolution autoradiographic imaging of radiolabeled 2-deoxyglucose and uptake. Prog Neurobiol 37:365-382.

Duncan GE, Breese GR, Criswell HE, Stumpf WE, Mueller RA, Covey JB (1986) Effects of antidepressant drugs injected into the amygdala on behavioral responses of rats in the forced swim test. J Pharmacol Exp Ther 238:758-762.

Duncan GE, Stumpf WE, Pilgrim C (1987) Cerebral metabolic mapping at the cellular level with drymount autoradiography of ${ }^{3} \mathrm{H}-2$ deoxyglucose. Brain Res 401:43-49.
Duncan GE, Paul IA, Powell KR, Fassberg JB, Stumpf WE, Breese GR (1989) Neuroanatomically selective down-regulation of beta adrenergic receptors by chronic imipramine treatment: relationship to the topography of ${ }^{3} \mathrm{H}$-imipramine and ${ }^{3} \mathrm{H}$-desipramine binding sites. $\mathrm{J}$ Pharmacol Exp Ther 248:470-477.

Duncan GE, Kaldas RG, Mitra KE, Breese GR, Stumpf WE (1990) High activity neurons in the reticular formation of the medial oblongata: a high-resolution autoradiographic 2-deoxyglucose study. Neuroscience 35:593-600.

Glass DC (1977) Bchavior patterns, stress and coronary disease. New York: Wiley.

Gorka Z, Ossowska K, Stach R (1979) The effect of unilateral amygdala lesion on the imipramine action in behavioral despair in rats. J Pharm Pharmacol 31:647-648.

Gross PM, Kadekaro M, Sokoloff L, Holcomb HH, Saavedra JM (1985) Alterations of local cerebral glucose utilization during chronic dehydration in rats. Brain Res 330:329-336.

Herve D, Tassin JP, Barthelemy C, Blanc G, Lavielle S, Glowinski J (1979) Difference in the reactivity of the mesocortical dopaminergic neurons to stress in the Balb/C and c57 BL/6 mice. Life Sci 25:16591664.

Honkaniemi J, Kainu T, Ceccatelli S, Rechardt L, Hokfelt T, PeltoHuikko M (1992) Fos and Jun in rat central amygdaloid nucleus and paraventricular nucleus after stress. Ncurorcport 3:849-852.

Johnson KB, Criswell HE, Jensen KF, Simson PE, Mueller RA, Breese GR (1992) Comparison of the D1-dopamine agonists SKF-38393 and A-68930 in neonatal 6-OHDA-lesioned rats: behavioral effects and induction of c-fos immunoreactivity. J Pharmacol Exp Ther 262: $855-865$.

Justice A, Feldman SM, Brown LL (1989) The nucleus locus coeruleus modulates local cerebral glucose utilization during noise stress in rats. Brain Res 490:73-84.

Kadekaro M, Vance WH, Terrell ML, Gary H Jr, Eisenberg HM, Sokoloff L (1987) Effects of antidromic stimulation of the ventral root on glucose utilization in the ventral horn of the spinal cord in the rat. Proc Natl Acad Sci USA 84:5492-5495.

Krettek JE, Price JL (1978) Amygdaloid projects to subcortical structures within the basal forebrain and brainstem in the rat and cat. $J$ Comp Neurol 178:225-254.

Lavielle S, Tassin J-P, Thierry A-M, Blanc G, Herve D, Barthelemy C, Glowinski J (1978) Blockade by benzodiazepines of the selective high increase in dopamine turnover induced by stress in mesocortical dopaminergic neurons of the rat. Brain Res 168:585-594.

Mata M, Fink DJ, Gainer H, Smith CB, Davidsen L, Savaki H, Schwartz WJ, Sokoloff L (1980) Activity-dependent energy metabolism in rat posterior pituitary primarily reflects sodium pump activity. I Neurochem 34:213-215.

Merchenthaler I, Vigh S, Petrusz P, Schally AV (1982) Immunocytochemical localization of corticotropin-releasing hormone in primate pituitary gland. J Clin Endocrinol Metab 64:1036-1041.

Morgan JJ, Cohen DR, Hempstead JL, Curran T (1987) Mapping patterns of c-fos expression in the central nervous system after seizure. Science 237:192-197.

Ordway GA, Gambarana C, Tejani-Butt SM, Areso P, Miroslawa H, Frazer A (1991) Preferential reduction of binding of ${ }^{125}$ I-iodopindolol to $\beta$-1 adrenoceptors in the amygdala of rat after antidepressant treatments. J Pharmacol Exp Ther 257:681-690.

Paul IA, Duncan GE, Kuhn C, Mueller RA, Jau-Shyong H, Breese GR (1990) Neural adaptation in imipramine-treated rats processed in forced swim test: assessment of time course, handling, rat strain and amine uptake. J Pharmacol Exp Ther 252:997-1005.

Pezzone MA, Lee WS, Hoffman GE, Rabin BS (1992) Induction of c- $f o s$ immunoreactivity in the forebrain by conditioned and unconditioned aversive stimuli. Brain Res 597:41-50.

Porsolt RD, Anton A, Blavet N, Jalfre M (1978) Behavioral despair in rats: a new model sensitive to antidepressant treatments. Eur $\mathbf{J}$ Pharmacol 47:379-391.

Rivier C, Brownstein M, Spies J, Rivier J, Vale W (1982) In vivo corticotropin-releasing factor-induced secretion of adrenocorticotropin $\beta$-endorphin, and corticosterone. Endocrinology 110:272-278.

Robertson HA, Peterson MR, Murphy K, Robertson GS (1989) D1dopamine receptor agonists selectively activate striatal c-fos dependent of rotational behavior. Brain Res 503:346-349.

Sagar SM, Sharp FR, Curran T (1988) Expression of c-fos protein in brain: metabolic mapping a the cellular level. Science 240:1328-1331. 
Sakanaka M, Magar S, Shibasaki T, Lederis K (1988) Corticotropin releasing factor-containing afferents to the lateral septum of the rat brain. J Comp Neurol 270:404-415.

Schwartz WJ, Smith CB, Davidsen L, Savaki H, Sokoloff L, Meta M, Fink DJ, Gainer H (1979) Metabolic mapping of functional activity in the hypothalamo-neurohypophysial system of the rat. Science 205: 723-725.

Sharp FR (1989) c-fos expression and $\left({ }^{14} \mathrm{C}\right)$ 2-deoxyglucose uptake in the caudal cerebellum of the rat during motor/sensory cortex stimulation. J Comp Neurol 284:621-636.

Sharp FR, Sager SM, Hicks K, Lowenstein D, Hisanaga K (1991) cfos mRNA, Fos, and Fos-related antigen induction by hypertonic saline and stress. J Neurosci 11:2321-2331.

Sheng M, Greenberg ME (1990) The regulation and function of c-fos and other immediate early genes in the nervous system. Neuron $4: 477$ 485.

Sokoloff L, Reivich M, Kennedy C, Des Rosiers MH, Patlak CS, Pet- tigrew KD, Sakuarado O, Shinohara M (1977) The $\left({ }^{14} \mathrm{C}\right)$ deoxyglucose method for the measurement of local cerebral glucose utilization: theory, procedure, and normal values in the conscious and anesthetized albino rat. J Neurochem 28:897-916.

Swanson LW (1983) The hippocampus and the concept of the limbic system. In: Neurobiology of the hippocampus (Seifert W, ed), pp 319. New York: Academic.

Thierry AM, Tassin JP, Blanc G, Glowinski J (1976) Selective activation of the mesocortical DA system by stress. Nature 263:242-244.

Trugman JM, Wooten GF (1987) Selective D1- and D2-dopamine agonists differentially alter basal ganglia glucose utilization in rats with unilateral 6-hydroxydopamine substantia nigra lesions. J Neurosci 7:2927-2935.

Trugman JM, James CL, Wooten FG (1991) D1/D2 dopamine receptor stimulation by $\mathrm{r}$-dopa. Brain 1 14:1429-1440.

Weiss JM (1971) Effects of punishing the coping response (conflict) on stress pathology in rats. J Comp Physiol Psychol 77:14-21. 